\title{
A protein of the SR family of splicing factors binds extensively to exonic Balbiani ring pre-mRNA and accompanies the RNA from the gene to the nuclear pore
}

\author{
Alla T. Alzhanova-Ericsson, Xin Sun, Neus Visa, Elena Kiseleva, Tilmann Wurtz, ${ }^{1}$ and Bertil \\ Daneholt ${ }^{2}$ \\ Department of Cell and Molecular Biology, Medical Nobel Institute, Karolinska Institutet, S-171 77 Stockholm, Sweden
}

\begin{abstract}
We report on the molecular cloning and intracellular localization of a heterogeneous nuclear ribonucleoprotein (hnRNP), Ct-hrp45, one of the major components of pre-mRNP particles in Chironomus tentans. It is shown that hrp45 belongs to the SR family of splicing factors and exhibits high sequence similarity to Drosophila SRp55/B52 and human SF2/ASF. The distribution of hrp45 within the C. tentans salivary gland cells is studied by immunocytology. The hrp45 protein is found to be abundant in the nucleus, whereas it is undetectable in the cytoplasm. The fate of hrp45 in specific pre-mRNP particles, the Balbiani ring (BR) granules, is revealed by immunoelectron microscopy. It is observed that hrp45 is associated with the growing BR pre-mRNP particles and is being added continuously concomitant with the growth of the transcript, indicating that hrp45 is bound extensively to exon 4 , which comprises $80-90 \%$ of the primary transcript. Furthermore, hrp45 remains bound to the BR RNP particles in the nucleoplasm and is not released until the particles translocate through the nuclear pore. Thus, hrp45 behaves as an hnRNP protein linked to exon RNA (and perhaps also to the introns) rather than as a spliceosome component connected to the assembly and disassembly of spliceosomes. It seems that hrp45, and possibly also other SR family proteins, is playing an important role in the structural organization of pre-mRNP particles and is perhaps participating not only in splicing but also in other intranuclear events.
\end{abstract}

[Key Words: SR proteins; hnRNP proteins; RNP particles; exon RNA; nucleo-cytoplasmic transport; nuclear pore]

Received July 15, 1996; revised version accepted September 18, 1996.

SR proteins comprise a family of evolutionarily conserved pre-mRNA splicing factors (Zahler et al. 1992; Birney et al. 1993; Fu 1995). Each protein contains one or two amino-terminal ribonucleoprotein (RNP)-type RNA recognition motifs (RRM) and a carboxy-terminal region rich in arginine-serine dipeptide repeats (RS domain). The SR proteins were identified initially because of a common epitope recognized by a monoclonal antibody (mAb 104), and they could be easily purified by a simple two-step salt precipitation procedure (Roth et al. 1991). Many organisms, ranging from Drosophila to humans, were found to contain a set of SR proteins of similar molecular masses: 20, 30, 40, 55, and $75 \mathrm{kD}$ (Zahler et al. 1992). In humans, the 30-kD fraction was shown to comprise two separate proteins, SRp30a and SRp30b (Zahler et al. 1992), that had earlier been described as SF2/ASF

\footnotetext{
${ }^{1}$ Present address: Center for Oral Biology, Karolinska Institutet, Box 4064, S-14104 Huddinge, Sweden.

${ }^{2}$ Corresponding author.
}

(Ge et al. 1991; Krainer et al. 1991) and SC35/PR264 (Fu and Maniatis 1992; Vellard et al. 1992), respectively. Each SR protein seems to have been strictly conserved during evolution; the SR protein of a given molecular mass is more similar to those of similar size in other species than it is to other SR proteins within its own species (Roth et al. 1991). New members of the SR family have been identified recently, and it is conceivable that the SR family is considerably larger than initially assumed (Blencowe et al. 1995; Neugebauer et al. 1995).

The SR proteins are essential splicing factors involved in both spliceosome assembly and the splicing process (for review, see Fu 1995). Different SR proteins seem to have similar, but not identical, functions in constitutive and regulated splicing. The individual SR proteins can restore general splicing activity to an $\mathrm{S100}$ extract /Ge et al. 1991; Krainer et al. 1991; Mayeda et al. 1992; Zahler et al. 1992; Screaton et al. 1995), but the activity differs between the SR proteins and is dependent on the premRNA species tested (Fu 1993). The SR proteins can also 
affect the choice of alternative splice sites in in vitro experiments (Ge et al. 1991; Krainer et al. 1991; Fu et al. 1992; Mayeda et al. 1992), but the individual SR proteins can favor different splice sites (Kim et al. 1992; Zahler et al. 1993a). Furthermore, there are also differences between the various SR proteins as to how they interact with exonic splicing enhancer elements (Sun et al. 1993b; Tian and Maniatis 1993/. Thus, it seems likely from the in vitro experiments that each SR protein has a unique function in constitutive and alternative splicing.

More recently, the effects of SR proteins have also been evaluated in vivo. In transfection experiments, it was shown that SR proteins can modulate alternative splicing in the same way as observed in vitro (Cáceres et al. 1994; Screaton et al. 1995; Wang and Manley 1995). However, differences were noted; for example, Wang and Manley (1995) observed that both SRp30a (SF2/ASF) and SRp30b (SC35) inhibit splicing of SV40 early pre-mRNA in vivo, whereas they stimulate in vitro. If SRp55/B52 is overexpressed in transgenic Drosophila flies, it affects the development of the organism seriously (Kraus and Lis 1994). In a more recent study, the corresponding gene was deleted, which interrupted development, indicating that SRp55/B52 plays a critical role in Drosophila development (Ring and Lis 1994). It was, however, not possible in this study to establish that splicing had been changed, although the splicing patterns of five specific pre-mRNAs were scrutinized. It can be concluded that the in vivo experiments confirm that SR proteins can influence the splicing process, but the in vivo situation is much more complex and the results are not easily interpreted. It is, of course, most important that the in vivo experiments clearly demonstrate that at least one of the SR proteins is critical for proper development (Ring and Lis 1994). Whether this effect is a result of aberrant splicing or is connected to failure of another cellular function remains to be demonstrated.

The SR proteins are present at the sites of transcription, which has been shown most convincingly in studies of the chromosome loops in amphibian oocytes (Roth et al. 1990) and the chromosome puffs in dipteran salivary glands (Champlin et al. 1991; Champlin and Lis 1994; Baurén et al. 1996). In mammalian cells, SR proteins are distributed in a speckled pattern (Fu and Maniatis 1990; Roth et al. 1990; Spector et al. 1991; Carter et al. 1993; Wansink et al. 1993) that on the ultrastructural level corresponds to perichromatin fibrils and interchromatin granule clusters (Spector et al. 1991). As perichromatin fibrils are known to contain newly synthesized heterogeneous nuclear RNA (hnRNA) (for review, see Fakan and Puvion 1980), this result supports the view that SR proteins associate with hnRNA, that is, premRNA, already during transcription. The early appearance of SR proteins on nascent transcripts is in agreement with the observation that splicing can occur cotranscriptionally (Osheim et al. 1985; Beyer and Osheim 1988; Le Maire and Thummel 1990; Baurén and Wieslander 1994). As splicing also takes place post-transcriptionally (for review, see Nevins 1983), it is to be expected that SR proteins are associated with at least some pre-mRNP in transit between the site of synthesis and the nuclear envelope. It has been difficult, however, to be more specific on the behavior of SR proteins in relation to the synthesis and flow of pre-mRNP particles; the light microscopic analysis in combination with in situ hybridization has been hampered by low resolution, and the ultrastructural analysis has not yet provided proper identification of gene-specific RNP fibrils or granules.

The precise role of SR proteins in the transcriptional and post-transcriptional events would benefit very much from studies of defined pre-mRNP particles carried out on the ultrastructural level with a concomitant assessment of the distribution of SR proteins. Now it has become feasible to perform such a study on the Balbiani ring transcription products in the salivary glands of the dipteran Chironomus tentans. The salivary gland cells contain polytene chromosomes, and the transcriptionally active regions appear as chromosomal puffs (Daneholt 1982). On chromosome IV, there are two giant puffs with exceptionally intense RNA synthesis: the Balbiani rings 1 and 2 (BR1 and BR2). The BR1 and BR2 genes, $35-40 \mathrm{~kb}$ in size, belong to the same gene family and exhibit a similar exon-intron organization with five exons and four introns (for review, see Wieslander 1994). A remarkable feature of the BR transcripts is that one of the exons (number 4$)$ is exceptionally long $(>30 \mathrm{~kb})$, whereas the introns and the other exons are relatively small $(<1.5 \mathrm{~kb})$ and located close to the $5^{\prime}$ or $3^{\prime}$ ends (Wieslander and Paulsson 1992). The three introns close to the $5^{\prime}$ end seem to be spliced before one-third of the transcript is synthesized, whereas the fourth intron close to the $3^{\prime}$ end is usually spliced post-transcriptionally (Baurén and Wieslander 1994). Small nuclear RNP particles (snRNPs) appear transiently on the growing RNP fibers at or close to the introns, reflecting the rapid assembly and disassembly of spliceosomes (Kiseleva et al. 1994). The synthesis of BR RNA and the packing of the RNA into RNP particles concomitant with transcription can be visualized in the electron microscope (Andersson et al. 1980; Olins et al. 1980; Skoglund et al. 1983). The completed product, a spherical particle with a diameter of $50 \mathrm{~nm}$, can be observed in the nucleoplasm (Stevens and Swift 1966; Skoglund et al. 1986; Mehlin et al. 1992) and also during translocation through the nuclear pore (Stevens and Swift 1966; Mehlin et al. 1992, 1995). Thus, the formation of the BR transcription product on the gene, the intranuclear transport, and the delivery of the transcript to the cytoplasm can be scrutinized on the ultrastructural level. Furthermore, with immunoelectron microscopy (immuno-EM) it has been demonstrated recently that the flow of a specific particle protein can be followed from the gene through the nuclear pore and into polysomes (Visa et al. 1996).

In the present study, we apply the BR system in the analysis of a specific SR protein. We have shown recently that the BR RNP particles contain a protein with an apparent molecular weight of $45 \mathrm{kD}$, designated Ct-hrp45 (or hrp45 for convenience) (Wurtz et al. 1996). Now we demonstrate that hrp45 possesses a high degree of sequence similarity to members of the SR protein family of 
splicing factors, including human SF2/ASF and Drosophila SRp55/B52. Using immuno-EM, we show that the putative splicing factor hrp45 binds to BR pre-RNA at multiple sites along the large exon, and perhaps along the entire transcript; this is in striking contrast to the behavior of snRNPs, which appear selectively at the intron regions of the transcript (Kiseleva et al. 1994). Furthermore, hrp45 accompanies BR pre-mRNA from the gene to the nuclear pore, where it is shed. We suggest that hrp45 is important for the structural organization of pre-mRNP particles and could be involved not only in splicing but also in other nuclear events.

\section{Results \\ Cloning and characterization of hrp45}

The mouse monoclonal antibody $2 \mathrm{E} 4$ recognizes the $C$. tentans hnRNP protein hrp45 (Wurtz et al. 1996). The specificity of the 2E4 antibody was demonstrated by Western blot analysis of nuclear and cytoplasmic samples from C. tentans tissue culture cells (Fig. 1). The 2E4 antibody reacts specifically with a $45-\mathrm{kD}$ protein, hrp45, that seems to be present in the nucleus (Fig. 1, lane a) but not in the cytoplasm (Fig. 1, lane b).

To determine the primary structure of hrp 45 , we used the 2E4 antibody to screen a C. tentans salivary gland, random-primed, lambda gt 11 cDNA library. Two cDNA clones, p1E1 and p1E9, were isolated. The sequence of their cDNA inserts turned out to be identical /data not shown); they were 907-bp long and contained a 109-bp 5' untranslated sequence (UTR) followed by an open reading frame (ORF) of $788 \mathrm{bp}$ with no stop codon at the $3^{\prime}$ end. Thus, the two clones harbored only a partial coding sequence.

To obtain a cDNA clone with the complete coding sequence, the PCR amplification product of the cDNA clone p1El was labeled with digoxigenin (DIG) and used as a probe to screen a C. tentans salivary gland, oligo(dT)primed, lambda ZAP cDNA library. Seven different cDNA clones were isolated and analyzed by sequencing. The nucleotide sequence of these clones comprises the full sequence of the insert in the p1E1 and the plE9 clones and additional sequences both at the $5^{\prime}$ and $3^{\prime}$ ends. The longest of the clones, pHRP45.1, presented in Figure 2, was shown to have a 1381-bp insert, including a 5' UTR (133 bp), a coding region (966 bp), and a $3^{\prime}$ UTR $(262 \mathrm{bp})$ followed by a poly(A) stretch. The $5^{\prime}$ UTR sequence preceding the initiation codon contains eight termination codons in frame. The 3' UTR sequence has a single polyadenylation signal AATAAA, which is located 15 nucleotides upstream of the $3^{\prime}$ poly(A) stretch, and is likely to represent an authentic $3^{\prime}$ end of the corresponding mRNA according to the requirements for a polyadenylation region (for review, see von Heijne 1988).

The putative translation initiation site, AAGATGGTT, is in agreement with Kozak's rule for initiation site consensus in eukaryotic mRNAs (Kozak 1986). The ORF in the pHRP45.1 sequence translates into 322 amino acids, starting at position 133 and ending with a
A

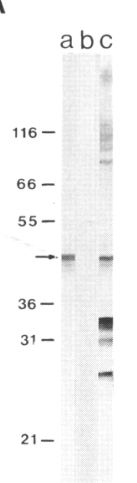

B

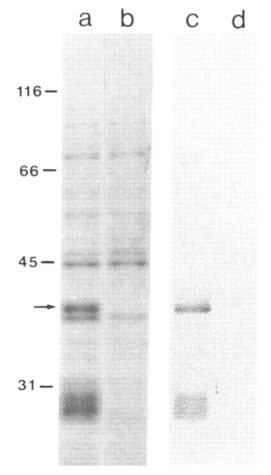

C

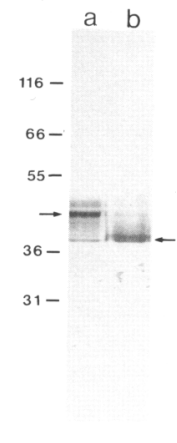

Figure 1. Mobility and immunoreactivity of hrp45 from $C$. tentans cells and of the cDNA-encoded protein expressed in bacteria. (A) Western blot analysis of hrp45 and SR proteins in extracts from $C$. tentans tissue culture cells. Proteins from nuclear (lanes $a, c)$ and cytoplasmic (lane $b$ ) fractions were separated by SDS-PAGE and blotted to transfer membranes. The membranes were cut into strips, and the strips were incubated with monoclonal antibodies against either hrp45 (mAb 2E4; lanes a,b) or SR proteins (mAbl04; lane $c$ ). $(B)$ Expression of the cDNA-encoded protein in E. coli. The coding region of pHRP45 was inserted into pET $21 \mathrm{~d}|+|$ vector, and after IPTG induction (lanes $a, c)$ or mock induction (lanes $b, d$ ), the proteins were analysed by SDS-PAGE followed by either Coomassie staining (lanes $a, b$ ) or Western blotting with mAb $2 \mathrm{E} 4$ (lanes $c, d)$. The induction of a $38-\mathrm{kD}$ protein specifically interacting with the $2 \mathrm{E} 4$ antibody can be observed. The broad band below $30 \mathrm{kD}$, which is present only after induction, is likely to be a product of degradation of the expressed protein. (C) Effect of dephosphorylation on the electrophoretic migration of hrp45 in SDS-PAGE. The C. tentans hrp45 protein was immunoprecipitated with mAb 2E4, submitted to dephosphorylation by alkaline phosphatase, and analyzed by Western blotting using the $2 \mathrm{E} 4$ antibody. (Lane a) Mobility of hrp45 (mock reaction); (lane b) mobility of hrp45 after digestion with alkaline phosphatase. The presence of multiple bands is likely to reflect different degrees of phosphorylation. The arrows point at the position of $C$. tentans hrp45 $(A, C)$ and the protein expressed in $E$. coli $(B)$. The mobility of molecular mass standards is given on the left (in kilodaltons).

stop codon at position 1101; the predicted molecular weight of the protein is 37,420 . Two amino acids are especially abundant, arginine $(65$ residues, or $20 \%$ of the total amino acid content) and serine (52 residues, or $16 \%$ of the total content), and both are mainly located in the carboxy-terminal part. At positions 193-212 in the carboxy-terminal part, there is a putative bipartite nuclear localization signal (Dingwall and Laskey 1991). The ORF sequence of the clone HRP45.1 was confirmed by analysis of the six additional cDNA clones.

To demonstrate that the protein encoded in the isolated cDNA clones is indeed recognized by the 2E4 antibody, the protein was expressed in E. coli. A protein of the expected molecular size, $37-38 \mathrm{kD}$, appeared among the bacterial proteins (Fig. 1B, cf. lanes a and b), and in a Western blot experiment the antibody reacted exclusively with this protein (Fig. 1B, cf. lanes c and d). It 


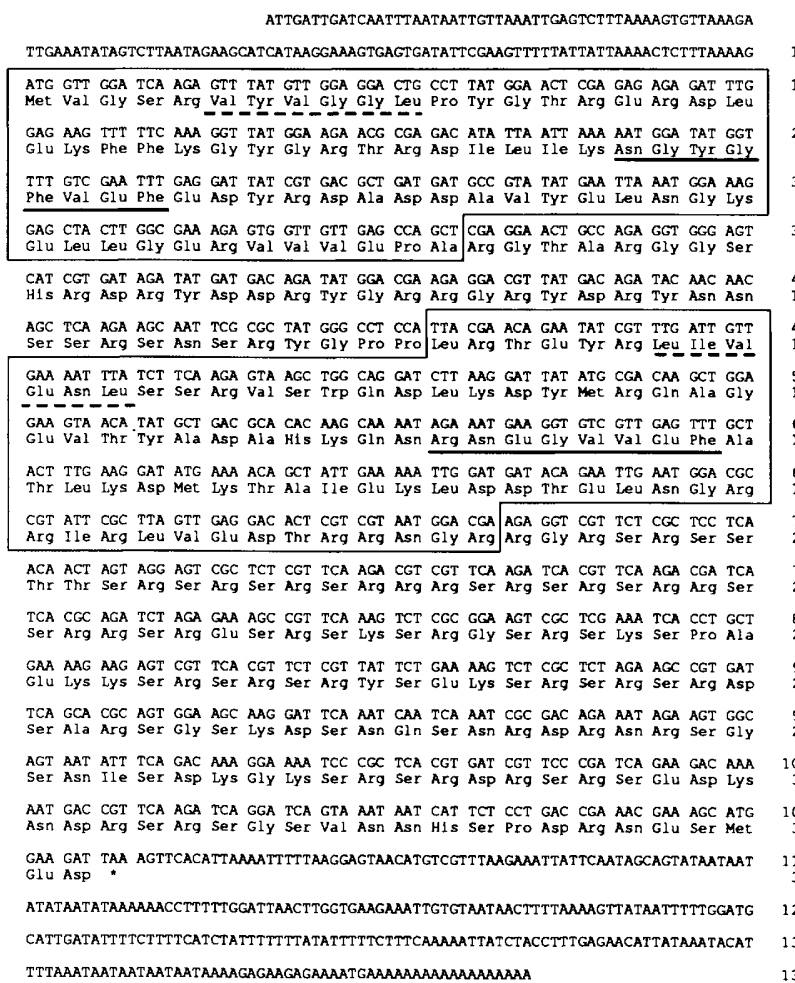

53

192

Figure 2. Nucleotide and predicted amino acid sequence of pHRP45.1 cDNA clone. The RNA binding domains, RRM 1 and RRM 2, are boxed. Within each RRM, the two most highly conserved sequence elements, RNP-1 (solid line) and RNP-2 (dashed line) are underlined. The end of the coding region is indicated by an asterisk. This sequence data has been deposited in the EMBL DNA data base under accession no. Z54163.

should be noted that the apparent molecular weight of the expressed protein is smaller than that of the C. tentans hrp45 $(45 \mathrm{kD})$. This discrepancy is likely to be caused by extensive phosphorylation of the cellular hrp45, as the apparent molecular weight of hrp45 is shifted from $45 \mathrm{kD}$ to $38 \mathrm{kD}$ upon alkaline phosphatase treatment (Fig. 1C, cf. lanes a and b). Furthermore, the presence of a number of phosphate groups also accounts for the acidic behavior of hrp45 in NEPHGE (Wurtz et al. 1996); the isolelectric point of the protein encoded in the cDNA clones was calculated to be as high as 11.6. Thus, the protein encoded in the isolated cDNA clones is likely to represent the cellular hrp 45 recognized by the 2E4 antibody. This conclusion is further supported by a more detailed comparison of the nature of the deduced sequence and the properties of the hrp45 protein (see below).

hrp45 is an analog to the mammalian RNA splicing factor SF2/ASF and the Drosophila SRp55/B52 protein

Searches of the EMBL DNA data base (Rice et al. 1993) and the SWISS-PROT data base (Bairoch and Boeckmann 1993) revealed that hrp45 has a strong sequence similarity to the proteins of the SR family of RNA splicing factors. The most characteristic feature of these proteins is the RS domain (Zahler et al. 1992; Birney et al. 1993). The highest score, $\sim 78 \%$ identity and $\sim 84 \%$ similarity, was obtained with the Drosophila protein SRp55/B52 (Champlin et al. 1991; Roth et al. 1991). Furthermore, hrp 45 shows $\sim 48 \%$ identity and $\sim 64 \%$ similarity to the human splicing factor SF2/ASF (Ge et al. 1991; Krainer et al. 1991). A direct alignment of hrp45 with SRp55 and SF2 highlights the sequence conservation between the three proteins (Fig. 3A). Sequence conservation is higher in the amino-terminal than in the carboxy-terminal part.

SF2/ASF has a modular primary structure comprising two RRMs and an auxiliary RS domain (Ge et al. 1991; Krainer et al. 1991); a small fourth domain, exhibiting a weak similarity to the RS domain, has also been recognized more recently between the two RRMs (Kim et al. 1992). As shown in the DOTPLOT comparison in Figure $3 \mathrm{~B}$, hrp45 has the same modular structure; regions A and $C$ correspond to the two RRMs, region $B$ to the small intervening domain, and region $\mathrm{D}$ to the carboxy-terminal RS domain. The sequences of the two RRMs in hrp45 are very similar to the RRMs in SF2 and Drosophila SRp55 (Fig. 3A). Region B in hrp45 is not only rich in arginines, but it is also relatively rich in glycines, although it does not contain a stretch of glycines, which is characteristic for SF2/ASF (Ge et al. 1991; Krainer et al. 1991). The RS domain in hrp45 is about three times longer than in SF2/ASF, but still shorter than the RS domain in SRp55/B52.

The conclusion that hrp45 is an SR protein is supported from several experimental observations on the properties of hrp45. First, as mentioned above, hrp45 is heavily phosphorylated, which is a characteristic of SR proteins (Roth et al. 1991; Zahler et al. 1993b). Furthermore, the mAb 104 antibody, which is known to be specific for SR proteins (Roth et al. 1991), reacts with a nuclear $45-\mathrm{kD}$ protein in $C$. tentans tissue culture cells as shown by Western blotting; the hrp45 protein constitutes one of three predominant SR proteins (Fig. 1A, lane c). In a follow-up experiment, the $45-\mathrm{kD}$ protein was immunoprecipitated from the nuclear extract by $2 \mathrm{E} 4$ and in a subsequent Western blot analysis shown to be recognized by the 104 antibody (data not shown). Finally, it has been observed that the $2 \mathrm{E} 4$ antibody also recognizes the SR protein SF2/ASF (A. Alzhanova-Ericsson, A. Kanopka, Y. Aissouni, G. Akusjärvi and B. Daneholt, in prep.), indicating that hrp45 and SF2/ASF have the 2E4 epitope in common; it should be noted that this epitope has to be different from the phospho-epitope recognized by mAbl04 (Roth et al. 1991), as it is insensitive to dephosphorylation (Fig. 1C). Thus, the observed properties of cellular hrp45 are in agreement with the prediction from the cDNA sequence that hrp45 is an SR protein.

\section{hrp45 is confined to the cell nucleus}

To determine the intracellular distribution of hrp45, the 2E4 antibody was used for immunocytology on semithin cryosections of fixed salivary glands. This assay at the light microscopy level provided information on the gen- 


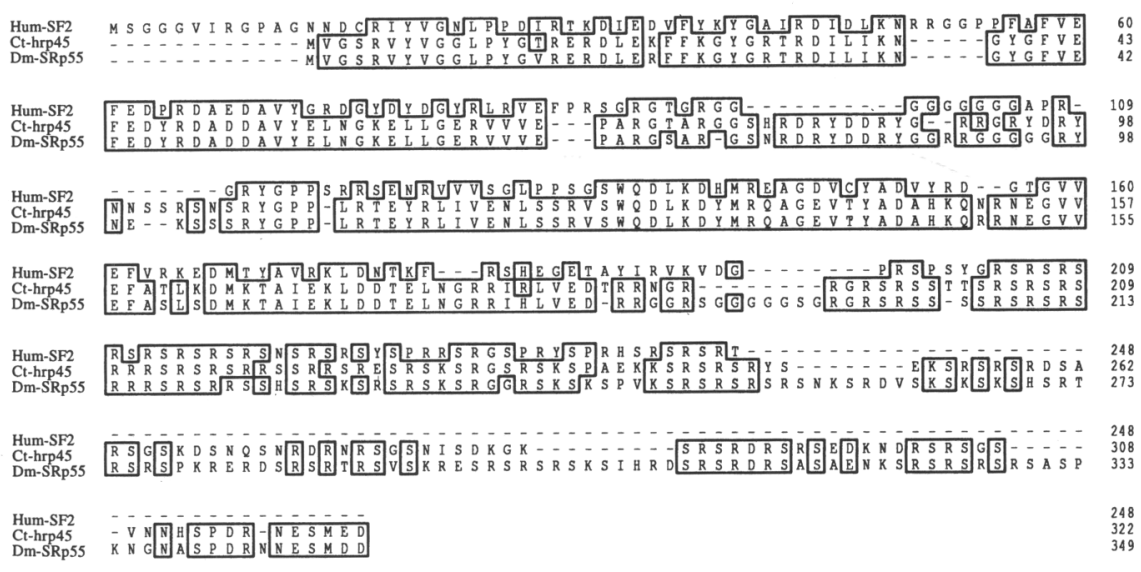

B

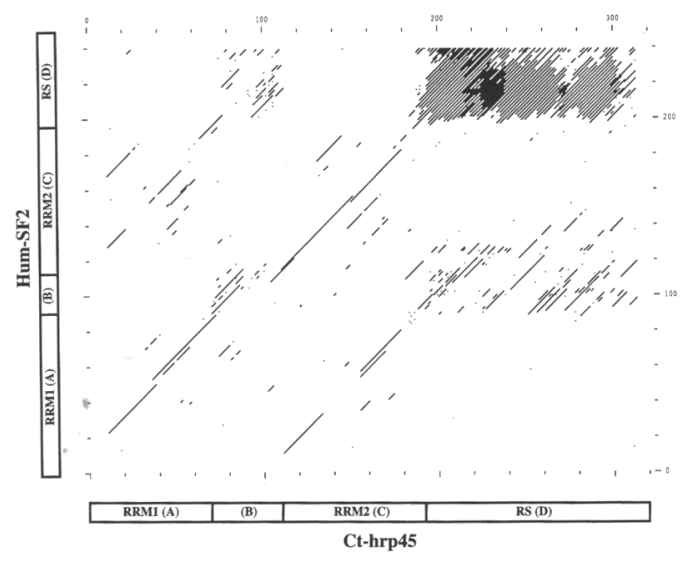

Figure 3. Sequence comparison of $\mathrm{Ct}$ hrp45 with human SF2 and Dm-SRp55. (A) The complete amino acid sequences of human SF2, Ct-hrp45, and Dm-SRp55 are aligned and presented by using the PILEUP and PRETTYPLOT programs. Regions with sequence similarity are boxed. Gaps in the alignment are shown by dashes. $(B)$ The amino acid sequences of Ct-hrp45 and human SF2 were compared and plotted using the COMPARE and DOTPLOT programs. Regions of significant matches are indicated with diagonal lines. Protein domains indicated by labeled boxes are drawn along the axis of the matrix. eral distribution of hrp45 in the cell compartments. Both the nucleus and the cytoplasm of the salivary gland cells could be readily identified by phase contrast microscopy (Fig. 4A). Observation of the same section under bright field conditions showed that immunostaining was restricted to the cell nucleus; no significant labeling was observed in the cytoplasm (Fig. 4A). The BRs were the most intensely labeled structures in the nucleus, but several other puffs as well as the nucleoplasm were stained. In the negative control, no labeling was detectable in either the nucleus or the cytoplasm of the salivary gland cells (Fig. 4, B and $B^{\prime}$ ). It was concluded that hrp45 is essentially confined to the cell nucleus (Fig. 1); the small amount of nascent hrp45 likely to be present in the cytoplasm is evidently below the detection limit of the method used.

\section{hrp45 accumulates in the BR RNP complexes concomitant with transcription}

To analyze the distribution of hrp 45 along the BR genes, we carried out immuno-EM on isolated polytene chromosomes using the $2 \mathrm{E} 4$ antibody. The isolated chromo- somes were fixed in $3.7 \%$ formaldehyde, challenged with antibodies, postfixed in $2 \%$ glutaraldehyde, embedded in plastic, sectioned, and stained (preembedding techniquel. The transcriptionally active BR genes could be visualized in the electron microscope as transcription loops (for review, see Daneholt 1992). At low magnification $B R 1$ and BR2 were easily recognized and segments of transcription loops discerned within the BRs (Fig. 5A). The assembly of the BR RNP complexes could be followed along the gene; in the promoter-proximal region, the nascent RNPs appear as thick RNP fibers growing longer and longer, whereas in the middle and distal regions the $5^{\prime}$ end of the RNP fiber is being packed into a dense globular structure that increases in diameter along the gene. Loop segments representing the various portions of the BR genes are denoted in Figure 5B: Thick RNP fibers are seen in proximal portions, small stalked granules in middle portions, and large stalked granules in distal portions. In our immuno-EM experiments, we studied the binding of the 2E4 antibody to the three loop segments to establish when hrp45 is being incorporated into the growing RNP particles.

The results of the immuno-EM experiments are presented in Figure 5C-E. There are gold particles over all 


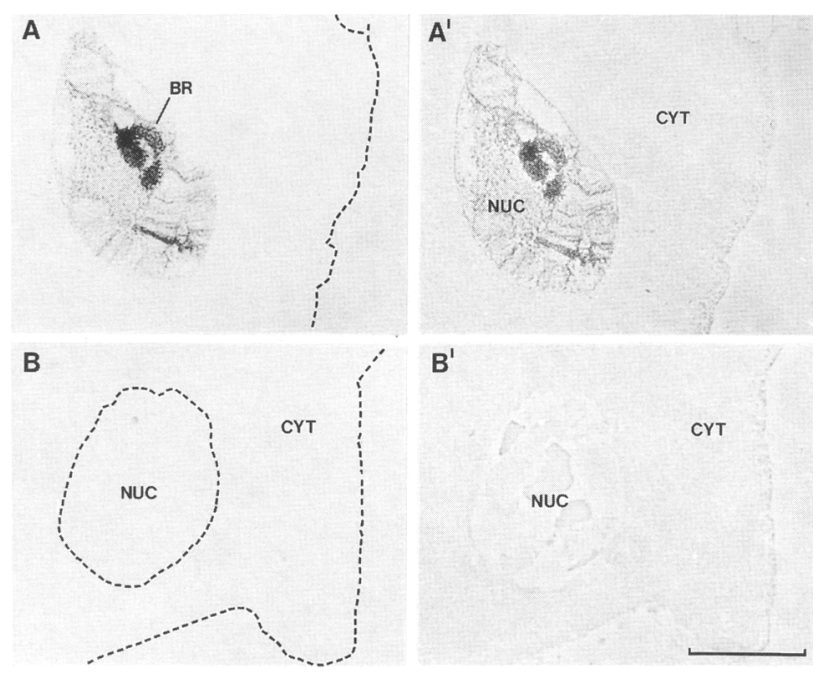

Figure 4. Distribution of $\mathrm{Ct}$-hrp45 in the salivary gland cells. A representative salivary gland section immunolabeled with $\mathrm{mAb}$ $2 \mathrm{E} 4$ is visualized and photographed by light microscopy. $(A)$ and $\left(A^{\prime}\right)$ show bright field and phase contrast images, respectively, of the same section. Note that the nucleus (NUC) is stained whereas the cytoplasm (CYT) is not stained. The most strongly labeled structures in the nucleus are the Balbiani rings (BR). $(B)$ and $\left(B^{\prime}\right)$ show bright field and phase contrast images, respectively, of a section treated with the negative control antibody. Dashed lines in the bright field images outline the nuclear and cytoplasmic compartments. Bar, $40 \mu \mathrm{m}$.

three regions: the proximal, middle, and distal regions. It is also evident that the signal grows stronger in parallel with the increase in size of the transcription product. No significant labeling was observed in the negative control (Fig. 5F). Thus, hrp45 seems to associate with nascent RNA early during transcription and is being added subsequently concomitant with the growth of the transcript.

To determine more accurately the appearance of hrp45 along the BR genes, the distribution of the gold particles among the three gene segments was established for BR 1 as well as for BR2 following the procedure described by Kiseleva et al. (1994). The quantitative analysis of the gold particles in the proximal, middle, and distal regions of the BR1 and BR2 loops is presented in Table 1. The increase in labeling along the gene is confirmed. Furthermore, the relative distribution of hrp45 in the proximal, middle, and distal segments corresponds well to the predicted relative amounts of growing BR RNA in the three segments (i.e., 1:3:5). Thus, it seems as if hrp45 is being added continuously to the growing RNP complex and that hrp45 is bound essentially along the entire length of both the BR1 and BR2 transcripts.

The 35-40-kb BR transcripts consist of $80-90 \%$ exon RNA; exon 4 is by itself $30-35 \mathrm{~kb}$ and one of the longest exons known (Wieslander 1994). Therefore, the observed distribution of hrp45 along the entire transcripts strongly suggests that hrp45 is bound extensively to exon RNA. Whether hrp45 is also bound to intron RNA

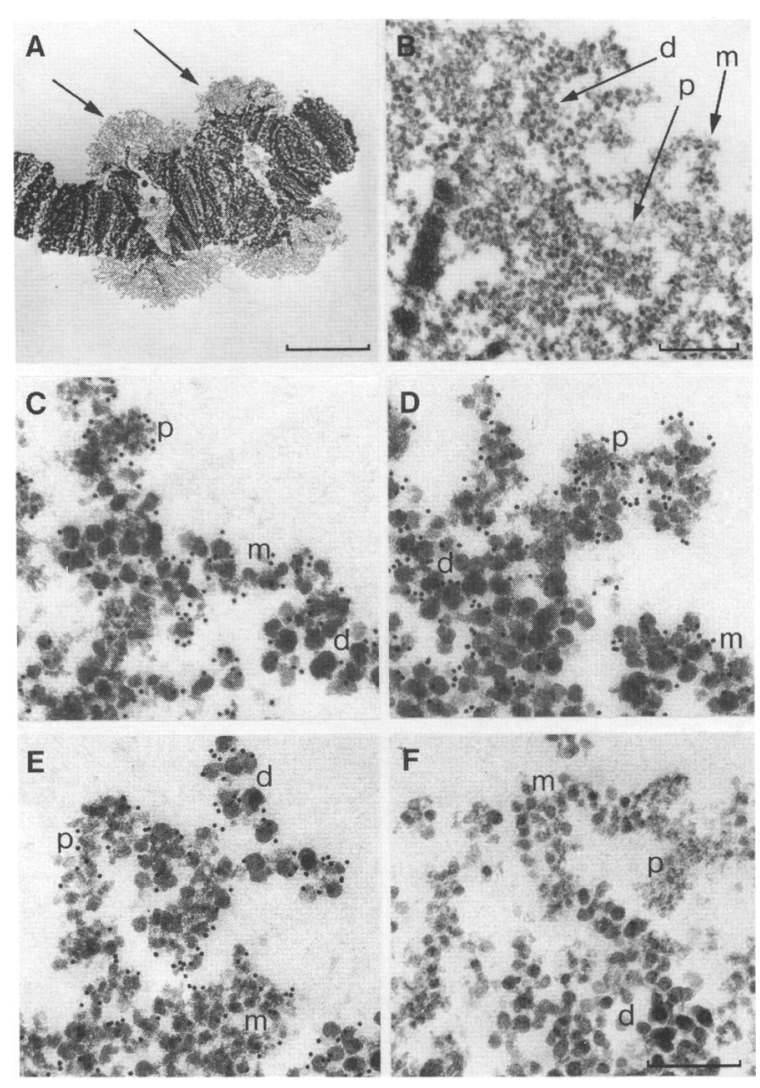

Figure 5. Electron micrographs of transcriptionally active BR genes and immuno-EM analysis of the distribution of hrp45 along BR transcription units. An isolated chromosome $\mathrm{IV}$ is shown in $A$; BR1 and BR2 are indicated by arrows. Proximal (p), middle $(\mathrm{m})$, and distal (d) regions of $B R$ transcription units are shown in $B$. Three examples of immunolabeling with mAb 2E4 against hrp45 are given in $C-E$; note the gradient of accumulation of gold labeling from proximal to distal regions of the transcription unit. No labeling can be seen with the negative control antibody $(F)$. Bar in $A, 5 \mu \mathrm{m}$; in $B, 0.5 \mu \mathrm{m}$; and in $F, 250 \mathrm{~nm}$ (magnification the same in $C-F$ ).

cannot be determined because the resolution of the method does not allow a sufficiently detailed analysis of the hrp45 distribution at the $5^{\prime}$ and $3^{\prime}$ ends of the transcripts, where the relatively short introns are located.

hrp45 is present in nucleoplasmic BR particles and in $B R$ particles translocating through the nuclear pores

To further follow the fate of hrp45, we studied the localization of hrp45 in BR RNP particles in sections of salivary glands using immuno-EM and the 2E4 antibody. In these experiments, the glands were fixed in $4 \%$ formaldehyde and $0.1 \%$ glutaraldehyde, cryoprotected, frozen, and sectioned. The immunoreactions were carried out on the sections, and subsequently the specimens were stained and embedded in polyvinyl alcohol. In spite of the relatively mild fixation, the ultrastructural morphology was adequate to allow the BR RNP particles to be 
Table 1. Quantitative immunoelectron microscopy analysis of the distribution of hrp 45 along transcription loops in BR1 and $B R 2$

\begin{tabular}{lcccl}
\hline & \multicolumn{3}{c}{ Regions } & \\
\cline { 2 - 4 } & proximal & middle & distal & Total \\
\hline BR1 & $699(11.5 \%)$ & $1949(32.2 \%)$ & $3424(56.3 \%)$ & $6072(100 \%)$ \\
BR2 & $720(12.5 \%)$ & $1818(31.5 \%)$ & $3241(56.0 \%)$ & $5779(100 \%)$ \\
\hline
\end{tabular}

The number of gold particles recorded in the proximal, middle, and distal regions of $\mathrm{BR} 1$ and $\mathrm{BR} 2$ transcription loops. BRs from six chromosomes (collected from six larvae) were studied; for each BR, three randomly chosen areas $(4 \times 6 \mu \mathrm{m})$ were selected for quantitative analysis. Each gold particle was referred to the proximal, middle, or distal region of a transcription loop. visualized in the BRs, in the nucleoplasm, and during pore passage.

As shown in Figure 6A, gold particles were found on growing BR RNP particles in the BRs, confirming the conclusion drawn above that hrp45 is being associated already with nascent BR RNA. The BR RNP particles are known to be released from the chromosome and appear in the nucleoplasm as dense RNP granules with a diameter of $\sim 50 \mathrm{~nm}$ (e.g., Mehlin et al. 1992). In our immunoEM experiments, the BR granules in the nucleoplasm were often decorated by gold particles; two examples are shown in Figure 6, B and C. Thus, hrp45 can still remain in the BR RNP particle during intranuclear transport.

BR RNP particles translocating through the nuclear pore are presented in Figure 6D-F. Labeling was observed on BR particles at this stage and the gold markers were
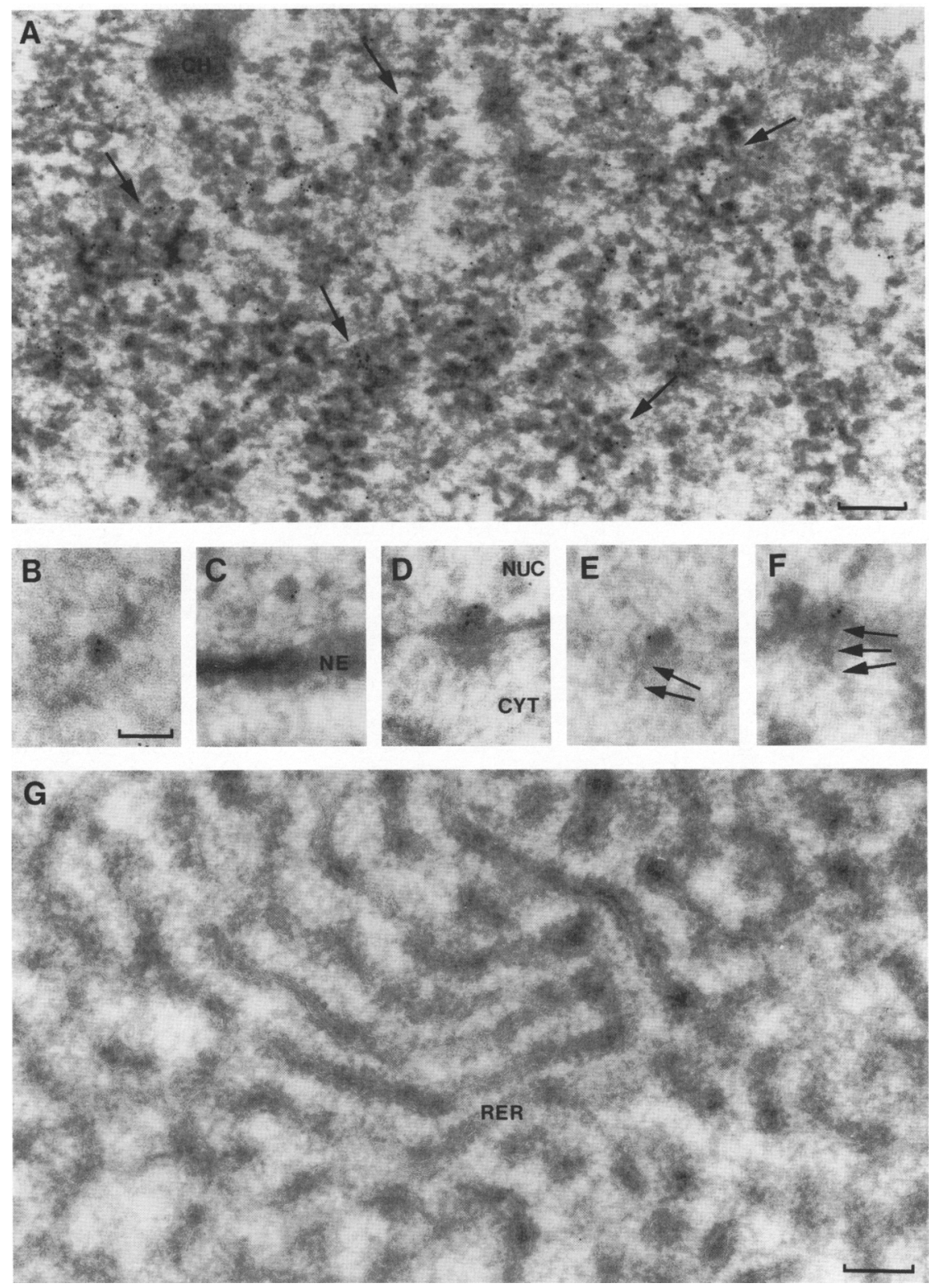

Figure 6. Immuno-EM localization of Cthrp45 in the salivary gland cells. The immunolabeling was performed on cryosections of fixed salivary glands as described in Materials and Methods. (A) Section through a BR puff showing nascent RNP particles characteristic of the giant transcription units. Abundant gold markers can be observed on the nascent RNP particles (arrows). In $B$ and $C$, mature BR premRNP particles in the nucleoplasm are labeled. The pre-mRNP particle shown in $C$ is close to the nuclear envelope (NE). $(D-F)$ Pre-mRNP particles at consecutive stages of translocation through the nuclear pore. All the photographs are oriented with the nucleus (NUC) in the top part of the image and the cytoplasm (CYT) in the bottom. Note that labeling is restricted to the nuclear portions of the translocating particles, whereas the fibers extending into the cytoplasm (arrows in $E$ and $F$ ) are not decorated by gold particles. (G) Cytoplasm of a salivary gland cell. Note the abundant tubular formations of rough endoplasmic reticulum (RER) that is characteristic of this cell type. No significant labeling with $\mathrm{mAb}$ 2E4 can be seen in the cytoplasm. Bars in $A$ and $G, 200 \mathrm{~nm}$; bar in $B-F, 100 \mathrm{~nm}$. 
exclusively associated with the nuclear portion of the RNP particle in transit. As illustrated in Figure 6, E and $\mathrm{F}$, the portion of the RNP fiber extending into the cytoplasm was unlabeled. This indicates that hrp45 can reach the pore associated with BR RNA but that it is released from the particle in conjunction with the translocation of the particle through the pore. No significant labeling was found in the cytoplasm of the salivary gland cells (Fig. 6G), which is in agreement with the light microscopy data presented above (Fig. 4). Thus, the hrp45 protein does not enter the cytoplasm with the BR RNA molecule.

We conclude that hrp45 is added onto the nascent transcript concomitant with transcription, accompanies the pre-mRNA to the nuclear pore, and is released from the transcript during the translocation of the particle through the pore. To our knowledge, this is the first time it has been shown that a specific hnRNP protein reaches the nuclear pore as a constituent of an RNP particle, and is shed at or within the nuclear pore complex, when the RNA enters cytoplasm.

\section{Discussion \\ hrp45 is an SR protein}

The sequence analysis of hrp45 revealed that hrp45 belongs to the family of SR proteins, which are known to act as pre-mRNA splicing factors. A high degree of sequence similarity was observed to human SF2/ASF /Ge et al. 1991; Krainer et al. 1991) and Drosophila SRp55/ B52 proteins (Champlin et al. 1991; Roth et al. 1991). The hrp45 protein has the same domain structure as SF2/ASF (and SRp55/B52); it contains two RRMs (regions $\mathrm{A}$ and $\mathrm{Cl}$, a relatively short arginine-rich region between the RRMs (region B), and a carboxy-terminal RS domain (region $\mathrm{D}$ ).

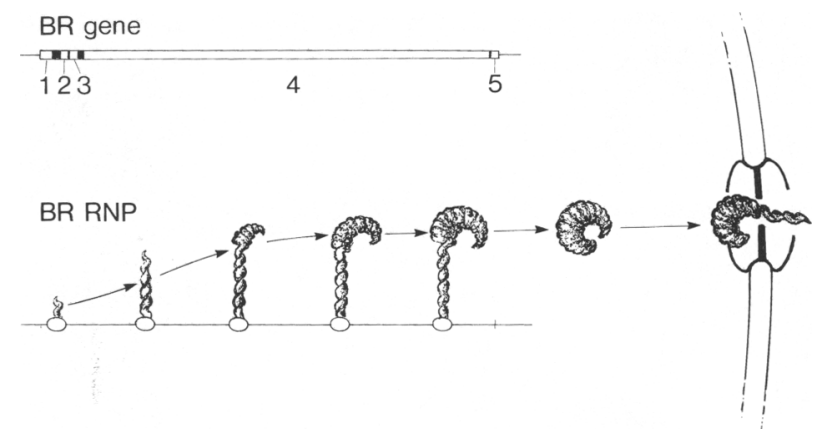

Amount hrp 45

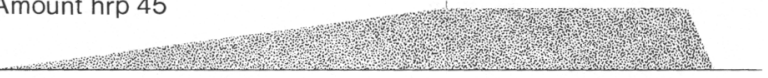

Figure 7. The assembly and transport of a BR pre-mRNP particle and the amount of hrp45 in the particle. The intron-exon arrangement in the BR gene is displayed in the upper part of the figure; the five exons $(1-5)$ are indicated. The lower part of the figure shows schematically how hrp45 is being associated with nascent BR RNA concomitant with transcription, that it is present in the mature BR particle, and that it is released when the particle is translocated through the nuclear pore.
Similar to SRp55 (Mayeda et al. 1992), hrp45 can substitute for SF2/ASF in an in vitro constitutive splicing system (A. Alzhanova-Ericsson, A. Kanopka, Y. Aissouni, G. Akusjärvi, and B. Daneholt, in prep.). Therefore, hrp45 is not only structurally similar, but also functionally related to human SF2/ASF and SRp55/B52, and probably to other SR proteins. The members of the SR family seem to have similar or overlapping functions in the splicing of different pre-mRNA substrates because there are observations of both redundancy and substrate specificity of these proteins (see the introductory section). We have shown that hrp 45 can be detected only at some, but not all chromosome puffs on C. tentans chromosomes (Wurtz et al. 1996). This result is in agreement with the view that hrp45 is a splicing factor with a differential substrate specificity: It seems to act on some but not all pre-mRNA substrates.

\section{hrp45 is distributed along the BR transcript}

The BR system allowed us to investigate the localization of hrp45 along growing pre-mRNP particles in situ. It was found that hrp45 is added cotranscriptionally to the growing BR pre-mRNA, and the amount of hrp45 is increasing in parallel with the growth of the primary transcript (Fig. 7). This result is in agreement with the earlier observation that hrp45 is an abundant protein in BR particles and that it is distributed along the RNP fiber of unfolded BR particles (Wurtz et al. 1996). Thus, hrp45 appears to be frequently bound along the BR transcript. As the transcript is dominated by exon 4, representing $80-90 \%$ of the entire transcript, it can be concluded that hrp45 binds extensively along this exceptionally large exon. The immuno-EM technique used here is not sensitive enough to establish whether hrp 45 is also bound to the other, smaller exons and to the four introns. Antibody labeling of growing RNPs on both the most promoter-proximal and the most promoter-distal parts of the BR genes suggests, however, that hrp45 is likely to be present along the entire transcript. Such a result is in agreement with the observation that both SR proteins (Roth et al. 1991; Wu et al. 1991) and hnRNP proteins (Wu et al. 1991) are distributed along the entire loops in lampbrush chromosomes.

As an SR protein, hrp45 is likely to participate in the splicing process. The observed distribution of hrp45 along the BR transcript indicates, however, that most, if not all, hrp45 is not a constitutive component of spliceosomes. The appearance of spliceosomes along the active BR genes was studied recently by immuno-EM using antibodies to snRNP particles (Kiseleva et al. 1994). The antibody labeling was found to be restricted to the proximal third of the gene and to the very distal end of the gene; this distribution corresponds to the regions where the introns are located. It was concluded from this study that both the assembly and the disassembly of the spliceosomes are closely linked to the splicing process, the three $5^{\prime}$ end introns known to be spliced in the proximal third of the gene and the $3^{\prime}$ end intron at least to some extent spliced before the completed transcript is released 
from the template (Baurén and Wieslander 1994). Thus, the more or less even distribution of hrp45 along the transcript does not correspond to that expected for a spliceosome component.

It is conceivable that hrp45 is being added to the transcript immediately upon transcription and is present along the primary transcript when spliceosomes are assembled on pre-mRNA. Such a view is supported by recent studies that show that SR proteins promote the assembly of the earliest detectable splicing complexes (Staknis and Reed 1994) and, in fact, commit pre-mRNA to the splicing pathway (Fu 1993). Furthermore, it has been shown that SF2/ASF, presumably bound to premRNA, helps recruiting U1 snRNP to the 5 ' splice site (Kohtz et al. 1994; Jamison et al. 1995). The SR proteins are also involved in several of the subsequent steps in spliceosome assembly and in the splicing process (for review, see Fu 1995).

In this context, it should be emphasized that SR proteins are known to be associated with specific exon sequences, the splicing enhancers (Lavigueur et al. 1993; Sun et al. 1993b; Tian and Maniatis 1993; Staknis and Reed 1994), which stimulate splicing of the upstream intron (Reed and Maniatis 1986; Watakabe et al. 1991; $\mathrm{Xu}$ et al. 1993). The interaction between the SR proteins and the enhancer sequence can be direct (Lavigueur et al. 1993; Sun et al. 1993b) or through complex formation with specific binding factors (Tian and Maniatis 1994; Lynch and Maniatis 1995). The bound SR proteins promote splicing by interacting with the splicing factor $\mathrm{U} 2 \mathrm{AF}$, stimulating and/or stabilizing complexes assembled at the nearby 3' splice site (Wang and Manley 1995). As SR proteins can interact with each other and with other splicing factors (for review, see Fu 1995), it has been proposed that they exert their effect by forming a network of proteins between the enhancer sequence and the adjacent upstream 3' splice site (Staknis and Reed 1994). Whether or not the BR exon 4 has enhancer activity has not been established, but it is interesting to note that the exon has a high purine content $145 \%$ adenine and $20 \%$ guanine in the repeat unit of exon 4 of the BR2.1 transcript) (Sümegi et al. 1992), which is known to be a characteristic of most exonic enhancers (Lavigueur et al. 1993; Sun et al. 1993a; Xu et al. 1993, Tanaka et al. 1994; Lynch and Maniatis 1995). The remarkable observation in the present study is that hrp45 resides along the entire exon 4 rather than at a specific site close to the upstream intron. The simplest explanation would be that because the exon sequence is internally repetitive (Wieslander 1994), a binding site (and a putative enhancer) would be present in a large number of copies evenly distributed along the exon. It is less likely that the exonic hrp45 molecules specifically mediate a stimulatory effect of a downstream $5^{\prime}$ splice site enhancer (Robberson et al. 1990; Talerico and Berget 1990; Hoffman and Grabowski 1992; Staknis and Reed 1994), because in the case of BR exon 4 splicing of the upstream intron 3 is completed far ahead of the synthesis of the downstream intron 4 (Baurén and Wieslander 1994; Kiseleva et al. 1994). However, it is not excluded that the SR proteins bound along exon 4 could play a role in exon definition, a process crucial for proper splicing (Robberson et al. 1990). Finally, it should be noted that an hnRNP Al-like protein, Ct-hrp36, also appears along exon 4 (Visa et al. 1996), which could be functionally relevant as SR proteins and hnRNP Al are known to affect at least alternative splicing in an antagonistic manner (Mayeda and Krainer 1992; Mayeda et al. 1994; Cáceres et al. 1994).

\section{hrp45 remains bound to the $B R$ transcript from the gene to the nuclear pore}

Similar to other SR proteins (Fu and Maniatis 1990; Roth et al. 1990; Spector et al. 1991), hrp45 is essentially confined to the cell nucleus; the antibody labeling of cytoplasm is not above background. Our immunocytological analysis showed that hrp45 is present not only on the chromosomes but also in the nucleoplasm. Furthermore, in the immuno-EM analysis of the BR particles it could be demonstrated that hrp45 is associated with the particles in the nucleoplasm and in transit through the nuclear pores (Fig. 7). It has been shown earlier by immunoEM of isolated, unfolded BR particles that hrp45 is distributed along the BR transcript also in nucleoplasmic particles (Kiseleva et al. 1994), almost all of them containing fully spliced RNA (Baurén and Wieslander 1994).

Although it is clear that the hrp45 protein is present in BR particles at or within the nuclear pore complex, it is more difficult to decide whether all the hrp45 protein molecules remain associated with the RNA during the transport from the gene to the pore. It is difficult to compare accurately the antibody labeling of the clustered growing RNP particles with that of the solitary ones in the nucleoplasm and in the pore, although it is evident that the labeling is of the same order of magnitude. It is, therefore, unlikely that hrp45 has been removed substantially from the BR RNP complex during the intranuclear transport. Furthermore, as hrp45 is an abundant protein component in the BR particle (Wurtz et al. 1996), a major loss of hrp45 should affect the structure and composition of the BR particle. Comparisons of threedimensional reconstructions of growing BR particles on the genes, released particles in the nucleoplasm, and particles translocating through the pores did not indicate any such substantial losses of material from the particles inside the nucleus (Skoglund et al. 1986; Mehlin et al. 1992, 1995). Finally, and most important, it was shown by isopycnic centrifugation in $\mathrm{CsCl}$ gradients that essentially all nucleoplasmic BR particles have the same, well-defined protein to RNA ratio, indicating that there is no gradual loss of proteins from the particles (Wurtz et al. 1990). Therefore, we regard it as less likely that a considerable part of the hrp45 is being released in the nucleoplasm prior to the unfolding and disassembly of the particle at the pore complex (Fig. 7).

In conjunction with the translocation, hrp45 is being shed from the particle. It is not possible to decide more precisely when the release takes place, but most likely, hrp45 does not pass through the central channel of the 
nuclear pore complex. hrp45 would belong then to the nonshuttling group of hnRNP proteins (Piñol-Roma and Dreyfuss 1992; Dreyfuss et al. 1993).

Being distributed along the BR transcript and remaining associated with the transcript all the way to the nuclear pore, hrp45 shows the anticipated properties of a structural hnRNP protein and not those of a spliceosome component. This suggests that apart from its effects on splicing, other functions should be considered for hrp45. It is likely to participate in the packing of the BR RNA into a well defined higher-order RNP structure: a 7-nm RNP fiber (Lönnroth et al. 1992) tightly folded into an RNP ribbon that is being bent into a ring (Skoglund et al. 1986). It is also conceivable that hrp 45 could affect the properties of the BR particle in processes such as interactions with the nuclear matrix, intranuclear transport, binding to the nuclear pore complex, and translocation through the central channel of the pore complex. Two recent studies in mammalian cells also support a postsplicing role for SR proteins. First, it was demonstrated that some SR proteins stay bound to the splicing complexes through both steps of the splicing reaction and also remain in the exon-product complex (Blencowe et al. 1995). Second, it was shown that overexpression of the SR protein SC35 can inhibit splicing and can result in accumulation of unspliced pre-mRNA that is transported efficiently into cytoplasm, indicating that SR proteins can affect the stability and/or facilitate transport of pre-mRNA (Wang and Manley 1995). Thus, the hrp45 data, as well as other lines of evidence, suggest that SR proteins could be active not only in splicing but also in other processes within the cell nucleus.

\section{Materials and methods}

\section{Experimental material}

C. tentans larvae were raised under laboratory conditions (Lezzi et al. 1981). C. tentans tissue culture cells were grown in suspension at $24^{\circ} \mathrm{C}$ as described by Wyss (1982).

\section{Antibodies}

The mouse monoclonal antibody $2 \mathrm{E} 4$ against $C$. tentans hrp45 was prepared in our laboratory as described (Wurtz et al. 1996) and used either as purified antibody or as 2E4-hybridoma supernatant as indicated. A monoclonal mouse anti-human von Willebrand factor antibody (DAKO-vWf , F8/86) was used as a primary antibody negative control for immunocytology and immuno-EM. The monoclonal antibody mAbl04 (American Type Culture Collection No. CRL-2067) was used to detect SR proteins (Roth et al. 1990).

\section{SDS-PAGE and Western blot analysis}

Protein extracts for Western blot analysis were prepared and analyzed as described by Wurtz et al. (1996). B-Glycerophosphate was added to all buffers at $5 \mathrm{~mm}$ to inhibit endogenous phosphatase activities. C. tentans tissue culture cells were homogenized in TNM buffer $[10 \mathrm{mM}$ triethanolamine- $\mathrm{HCl} / \mathrm{pH}$ 7.0), $100 \mathrm{mM} \mathrm{NaCl}$, and $1 \mathrm{mM} \mathrm{MgCl}_{2}$ ] containing $0.2 \% \mathrm{NP}-40$ and $0.1 \mathrm{mM}$ PMSF using a glass tissue grinder. The homogenate was centrifuged at $2000 \mathrm{~g}$ for $5 \mathrm{~min}$ at $0^{\circ} \mathrm{C}$ and the resulting supernatant constituted the cytoplasmic extract used for West- ern blot analysis. The pellet was washed with TNM, and RNP extracts I and II were prepared according to Wurtz et al. (1996). The RNP extracts I and II were combined and used as nuclear fraction for Western blot analysis. In all cases, the proteins were precipitated with acetone, separated by electrophoresis in SDSpolyacrylamide gels, and transfered to PVDF membranes (Millipore) using a semidry electrophoretic system (BioRad Labs). The membranes were cut into strips, blocked with $10 \%$ nonfat dry milk in PBS for $1 \mathrm{hr}$, and incubated with the first antibody (hybridoma supernatant from clone 104 diluted $1 / 100$ or $2 \mathrm{E} 4$ diluted $1 / 1000$ ) in PBS containing $1 \%$ dry milk and $0.05 \%$ Tween-20. Labeling was visualized with alkaline phophataseconjugated anti-mouse immunoglobulins using the NBT/BCIP system (Promega).

\section{Immunoprecipitation and alkaline phosphatase treatment}

Immunoprecipitation of hrp45 from RNP extract I was performed essentially as described by Wurtz et al. (1996) using mAb 2E4 directly cross-linked to protein G-agarose (Zymed Laboratories, Inc). After $1.5 \mathrm{hr}$ of incubation at $4^{\circ} \mathrm{C}$, the resin was sedimented and washed three times with PBS containing $0.1 \%$ $\mathrm{NP}-40$. The washed resin was resuspended in $50 \mathrm{~mm}$ Tris- $\mathrm{HCl}$ (pH 9.0), $1 \mathrm{mM} \mathrm{MgCl}_{2}, 0.1 \mathrm{mM} \mathrm{ZnCl}_{2}$, and $1 \mathrm{~mm}$ spermidine and divided into two equal parts. One of them was treated with 100 $\mathrm{U} / \mathrm{ml}$ calf intestine alkaline phosphatase (Boehringer Mannheim) for $10 \mathrm{~min}$ at $37^{\circ} \mathrm{C}$ to dephosphorylate hrp45. The other half was incubated in the same conditions without enzyme (mock reaction). In both cases, the hrp45 protein was finally eluted from the agarose resin with $0.5 \%$ SDS, precipitated with acetone, and analyzed by Western blot as described above.

\section{Isolation of cDNA clones}

Mouse mAb 2E4 was used at 1:1000 dilution to screen a random primed lambda gt 11 cDNA library from salivary glands of $C$. tentans with ProtoBlot Immunoscreening System (Promega Biotech) according to the manufacturer's instructions. Purified positive plaques were used directly as a source of template DNA for PCR amplification with GeneAmp PCR Core Reagents (Perkin Elmer Cetus) and lambda gt 11 forward and reverse primers (Promega Biotech). The Magic PCR Preps DNA Purification System (Promega Biotech) was used for purification of DNA fragments amplified by PCR. PCR-amplified DNA fragments were nonradioactively labeled with the DIG-System of Nonradioactive Labeling and Detection (Boehringer Mannheim) and used for screening an oligo(dT)-primed lambda ZAP cDNA library from the salivary glands of $C$. tentans.

DNA sequencing and sequence analysis

To avoid subcloning, we PCR-amplified cDNA inserted into either lambda gtll or lambda ZAP cDNA and used the amplified DNA as a source of DNA template for sequencing with walking primers. Nucleotide sequencing was carried out with Taq DyeDeoxy Terminator Cycle Sequencing Kit (Applied Biosystems) using double-stranded DNA templates. Multiple synthetic oligonucleotides (20-mers or longer) were used to sequence both DNA strands. The sequencing gel was run on a 373A Automated DNA Sequencer (Applied Biosystems). Sequence analysis was performed with the University of Wisconsin Genetics Computer Group Sequence Analysis programs (Devereux et al. 1984) and EGCG extensions to the Wisconsin Package Sequence Analysis programs.

\section{Expression of cDNA-encoded protein in bacteria}

The cDNA clone pHRP45.1 was used as a template in a PCR reaction with Taq polymerase (Boehringer Mannheim) to am- 
plify the ORF. The oligonucleotides were designed to introduce a $N c o$ I restriction site at the $5^{\prime}$ end of the amplified PCR product and a BamHI site at the $3^{\prime}$ end. The PCR product was digested with $\mathrm{NcoI}$ and $\mathrm{BamHI}$ and inserted into the corresponding sites of the expression vector pET $21 \mathrm{~d}(+)$ (Novagen, Inc.). The resulting plasmid pET21d-hrp45 was transformed into E. coli BL21(DE3)LysS cells according to the protocol supplied by Novagen. Transformants resistant to both ampicillin and to chloramphenicol were selected and analyzed by sequencing. It was confirmed that the clone pET21d-hrp45-2 contains the cDNA insert with an ORF identical to the one in the original clone pHRP45.1. Therefore, clone pET2ld-hrp45-2 was used further for protein expression. Bacterial cultures grown in LuriaBertani medium with ampicillin and chloramphenicol were induced for $3 \mathrm{hr}$ with $0.4 \mathrm{~mm}$ isopropylthiogalactoside (IPTG) when their $\mathrm{OD}_{600}$ reached 1. IPTG-induced and mock-induced cells were harvested, washed in $0.14 \mathrm{NaCl}, 10 \mathrm{~mm}$ Tris- $\mathrm{HCl} / \mathrm{pH}$ 7.6), $1 \mathrm{~mm}$ dithiothreitol (DTT), and $100 \mathrm{~mm}$ phenylmethylsulfonyl fluoride (PMSF), boiled for $5 \mathrm{~min}$ in SDS-PAGE sample buffer, and analyzed by Coomassie staining and Western blotting.

\section{Immunocytology}

Immunolabeling on semithin (thickness $0.5 \mu \mathrm{m}$ ) cryosections was performed as described previously (Visa et al. 1996). Briefly, C. tentans salivary glands were fixed for $1 \mathrm{hr}$ with $4 \%$ formaldehyde in $0.1 \mathrm{M}$ cacodylate buffer $(\mathrm{pH} 7.2)$ at room temperature, cryoprotected with $2.3 \mathrm{~m}$ sucrose, and frozen by immersion in liquid nitrogen. Sections were obtained in a cryo-ultramicrotome Ultracut S/FC S (Reichert) and mounted on glass slides. Before immunolabeling, sections were blocked with $2 \%$ BSA in phosphate-buffered saline (PBS) [137 $\mathrm{mm} \mathrm{NaCl}, 3 \mathrm{~mm} \mathrm{KCl}, 8 \mathrm{~mm}$ $\mathrm{Na}_{2} \mathrm{HPO}_{4}$, and $2 \mathrm{~mm} \mathrm{NaH}_{2} \mathrm{PO}_{4}$ (pH 7.2)] with $0.1 \mathrm{M}$ glycine. As a first antibody, we used either undiluted 2E4-hybridoma supernatant or as a negative control $20 \mu \mathrm{g} / \mathrm{ml}$ anti-von Willebrand factor (DAKO). In the second step of immunostaining we used a gold-conjugated goat antibody against mouse IgG (AuroProbe EM GAM IgG G5, Amersham; $5 \mathrm{~nm}$ in diameter). The immunogold labeling was silver-enhanced with IntenSEM (Amersham).

\section{Immuno-EM on isolated chromosomes}

Transcription of BR genes was stimulated in vivo by adding pilocarpine nitrate to the cultivation water $(0.1 \mathrm{mg} / \mathrm{ml})$ and incubating larvae for $3-5 \mathrm{hr}$ at $22^{\circ} \mathrm{C}$ as described (Mähr et al. 1980). Salivary glands were dissected from fourth instar larvae and incubated for $30 \mathrm{sec}$ in $2 \% \mathrm{NP}-40$ in TKM buffer $[100 \mathrm{mM}$ $\mathrm{KCl}, 1 \mathrm{~mm} \mathrm{MgCl}_{2}$, and $10 \mathrm{~mm}$ triethanolamine- $\mathrm{HCl}$ (pH 7.0)], transferred to $0.025 \%$ NP40 in TKM, and disrupted by a pipetting technique to release polytene chromosomes. Individual chromosome IVs were identified, transferred, and attached to a siliconized glass depression slide (Björkroth et al. 1988). The isolated chromosomes were fixed with $3.7 \%$ formaldehyde in TKM for $30 \mathrm{~min}$ at room temperature and washed with three changes of TKM. Then, the chromosomes were incubated for 30 min at room temperature in a humid chamber on a rocking platform with $40 \mu \mathrm{l}$ of $1 \% \mathrm{BSA}$ in TKM and for 90 min with 40 $\mu l$ of the primary antibody, diluted in TKM to $1: 100$ for $2 \mathrm{E} 4$, or 1:5 for the negative control anti-human von Willebrand factor antibody (DAKO). The slides were washed three times for $5 \mathrm{~min}$ each in $0.1 \%$ Tween 20 in TKM and then incubated for $90 \mathrm{~min}$ with the gold-conjugated secondary goat anti-mouse antibody (AuroProbe EM GAM IgG G10; Amersham; $10 \mathrm{~nm}$ in diameter) diluted $1: 50$ in $0.5 \%$ BSA in TKM. After incubation with the gold-conjugated antibody, the specimens were washed three times for $5 \mathrm{~min}$ in TKM, fixed in $2 \%$ glutaraldehyde in TKM, washed as above in TKM, dehydrated in $90 \%$ ethanol, and embedded in Agar 100 resin (AGAR Scientific, LTD). Specimens of chromosome IV with well-preserved BR puffs were sectioned and stained with uranyl acetate and lead citrate as previously described (Björkroth et al. 1988). The specimens were examined and photographed in a JEOL TEM-SCAN $100 \mathrm{CX}$ microscope at $60 \mathrm{kV}$

For quantitative analysis of the distribution of the 2E4 antibody along the nascent BR transcripts, we chose six chromosome IVs from six larvae. Only sections through the center of the BRs were analyzed. The gold particles in BR1 and BR2 were studied separately. The location of all gold particles in three randomly chosen areas (each about $4 \times 6 \mu \mathrm{m}$ ) was studied, and each particle was referred to the proximal, middle, or distal region of a BR loop. The counts for each region were summed and percentages calculated.

\section{Immuno-EM on ultrathin cryosections}

Immuno-EM was carried out essentially as described (Tokuyasu 1980; Visa et al. 1996). The specimens were prepared as described above for light microscopy except that fixation was carried out for $20-25 \mathrm{~min}$ in $4 \%$ formaldehyde and $0.1 \%$ glutaraldehyde. Ultrathin cryosections were picked up on drops of $2.3 \mathrm{M}$ sucrose and deposited on nickel grids coated with formvar and carbon. The grids were floated on drops of PBS containing 10\% newborn calf serum (Gibco) before incubation with the antibody solutions. The same antibodies were used as described above for light microscopy. After immunolabeling, sections were stained with $2 \%$ aqueous uranyl acetate and embedded in polyvinyl alcohol $(9-10 \mathrm{kD}$; Aldrich). The specimens were examined and photographed in a JEOL TEM-SCAN $100 \mathrm{CX}$ microscope at $80 \mathrm{kV}$.

\section{Acknowledgments}

We thank K. Tokuyasu for generous support, expert advice on immuno-EM, and many fruitful discussions. We are grateful to L. Wieslander and J. Galli for kindly providing the cDNA libraries and for advice on the strategy of cloning. We thank L.-M. Fjelkestam, K. Gell, and J. Torudd for technical assistance and E. Magnusson for the artwork in Figure 7. This study was supported by the Swedish Natural Science Research Council, the Swedish Cancer Fund, Knut and Alice Wallenberg Foundation, Kjell and Märta Beijer Foundation, and Petrus and Augusta Hedlund Foundation. N.V. was a recipient of an EMBO long-term fellowship and a Human Capital and Mobility Individual Fellowship from the Commission of the European Communities. E.K. was a recipient of a stipend from the Royal Swedish Academy of Sciences/cooperation program between Sweden and former Soviet Union).

The publication costs of this article were defrayed in part by payment of page charges. This article must therefore be hereby marked "advertisement" in accordance with 18 USC section 1734 solely to indicate this fact.

\section{References}

Andersson, K., B. Björkroth, and B. Daneholt. 1980. The in situ structure of the active $75 \mathrm{~S}$ RNA genes in Balbiani rings of Chironomus tentans. Exp. Cell Res. 130: 313-326.

Bairoch, A. and B. Boeckmann. 1993. The SWISS-PROT protein sequence data bank, recent developments. Nucleic Acids Res. 21: 3093-3096.

Baurén, G. and L. Wieslander. 1994. Splicing of Balbiani ring 1 gene pre-mRNA occurs simultaneously with transcription. Cell 76: 183-192.

Baurén, G., W.-O. Jiang, K. Bernholm, F. Gu, and L. Wieslander. 1996. Demonstration of a dynamic, transcription-dependent 
organization of pre-mRNA splicing factors in polytene nuclei. J. Cell Biol. 133: 929-941.

Beyer, A.L. and Y.N. Osheim. 1988. Splice site selection, rate of splicing, and alternative splicing on nascent transcripts. Genes \& Dev. 2: 754-765.

Birney, E., S. Kumar, and A.R. Krainer. 1993. Analysis of the RNA-recognition motif and RS and RGG domains: Conservation in metazoan pre-mRNA splicing factors. Nucleic Acids Res. 21: 5803-5816.

Björkroth, B., C. Ericsson, M.M. Lamb, and B. Daneholt. 1988. Structure of the chromatin axis during transcription. Chromosoma 96: 333-340.

Blencowe, B.J., R. Issner, J. Kim, P. McCaw, and P.A. Sharp. 1995. New proteins related to the Ser-Arg family of splicing factors. RNA. 1: 852-865.

Cáceres, J.F., S. Stamm, D.M. Helfman, and A.R. Krainer. 1994. Regulation of alternative splicing in vivo by overexpression of antagonistic splicing factors. Science 265: 1706-1709.

Carter, K.C., D. Bowman, W. Carrington, F. Fogarty, J.A. McNeil, F.S. Fay, and J.B. Lawrence. 1993. A three-dimensional view of precursor messenger RNA metabolism within the mammalian nucleus. Science 259: 1330-1335.

Champlin, D.T. and J.T. Lis. 1994. Distribution of B52 within a chromosomal locus depends on the level of transcription. Mol. Biol. Cell 5: 71-79.

Champlin, D.T., M. Frasch, H. Saumweber, and J.T. Lis. 1991. Characterization of a Drosophila protein associated with boundaries of transcriptionally active chromatin. Genes \& Dev. 5: 1611-1621.

Daneholt, B. 1982. Structural and functional analysis of Balbiani ring genes in the salivary glands of Chironomus tentans. In Insect ultrastructure (ed. R. King and H. Akai), pp. 382-401. Plenum, New York, NY.

- 1992. The transcribed template and the transcription loop in Balbiani rings. Cell Biol. Int. Rep. 16: 709-715.

Devereux, J., P. Haeberli, and O. Smithies. 1984. A comprehensive set of sequence analysis programs for VAX. Nucleic Acids Res. 12: 387-395.

Dingwall, C. and R. Laskey. 1991. Nuclear targeting sequences-A consensus? Trends Biochem. Sci. 16: 478-481.

Dreyfuss, G., M.J. Matunis, S. Piñol-Roma, and C.G. Burd. 1993. hnRNP proteins and the biogenesis of mRNA. Annu. Rev. Biochem. 62: 289-321.

Fakan, S. and E. Puvion. 1990. The ultrastructural visualization of nucleolar and extranucleolar RNA synthesis and distribution. Int. Rev. Cytol. 65: 255-299.

Fu, X.-D. 1993. Specific commitment of different pre-mRNAs to splicing by single SR proteins. Nature 365: $82-85$. . 1995. The superfamily of arginine/serine-rich splicing factors. RNA 1: 663-680.

Fu, X.-D. and T. Maniatis. 1990. Factor required for mammalian spliceosome assembly is localized to discrete regions in the nucleus. Nature 343: 437-441.

- 1992. Isolation of a complementary DNA that encodes the mammalian splicing factor SC35. Science 256: 535-538.

Fu, X.-D., A. Mayeda, T. Maniatis, and A.R. Krainer. 1992. General splicing factors SF2 and SC35 have equivalent activities in vitro, and both affect alternative $5^{\prime}$ and $3^{\prime}$ splice site selection. Proc. Nat1. Acad. Sci. 89: 11224-11228.

Ge, H., P. Zuo, and J.L. Manley. 1991. Primary structure of the human splicing factor ASF reveals similarities with Drosophila regulators. Cell 66: 373-382.

Hoffman, B.E. and P.J. Grabowski. 1992. Ul snRNP targets an essential splicing factor, U2AF65, to the $3^{\prime}$ splice site by a network of interactions spanning the exon. Genes \& Dev. 6: 2554-2568.

Jamison, S.F., Z. Pasman, J. Wang, C. Will, R. Lührmann, J.L.
Manley, and M.A. Garcia-Blanca. 1995. U1 snRNP-ASF/SF2 interaction and 5' splice recognition: Characterization of required elements. Nucleic Acids Res. 23: 3260-3267.

Kim, Y.-J., P. Zuo, J.L. Manley, and B.S. Baker. 1992. The Drosophila RNA-binding protein RBP1 is localized to transcriptionally active sites of chromosomes and shows a functional similarity to human splicing factor ASF/SF2. Genes \& Dev. 6: 2569-2579.

Kiseleva, E., T. Wurtz, N. Visa, and B. Daneholt. 1994. Assembly and disassembly of spliceosomes along a specific premessenger RNP fiber. EMBO I. 13: 6052-6061.

Kohtz, J.D., S.F. Jamison, C.L. Will, P. Zuo, R. Lührmann, M.A. Garcia-Blanco, and J.L. Manley. 1994. Protein-protein interactions and 5 '-splice-site recognition in mammalian mRNA precursors. Nature 368: 119-124.

Kozak, M. 1986. Point mutations define a sequence flanking the AUG initiator codon that modulates translation by eukaryotic ribosomes. Cell 44: 283-292.

Krainer, A.R., A. Mayeda, D. Kozak, and G. Binns. 1991. Functional expression of cloned human splicing factor SF2: Homology to RNA-binding proteins, Ul $70 \mathrm{~K}$, and Drosophila splicing regulators. Cell 66: 383-394.

Kraus, M.E. and J.E.T. Lis. 1994. The concentration of B52, an essential splicing factor and regulator of splicing site choices in vitro, is critical for Drosophila development. Mol. Cell. Biol. 14: 5360-5370.

Lavigueur, A., H. La Branche, A.R. Kornblihtt, and B. Chabot. 1993. A splicing enhancer in the human fibronectin ED1 exon interacts with SR proteins and stimulates snRNP binding. Genes \& Dev. 7: 2405-2417.

Le Maire, M.F. and C.S. Thummel. 1990. Splicing precedes polyadenylation during Drosophila E74A transcription. Mol. Cell. Biol. 10: 6059-6063.

Lezzi, M., B. Meyer, and R. Mähr. 1981. Heat shock phenomena in Chironomus tentans. I. In vivo effects of heat, overheat, and quenching on salivary chromosome puffing. Chromosoma 83: 327-339.

Lönnroth, A., K. Alexciev, H. Mehlin, T. Wurtz, U. Skoglund, and B. Daneholt. 1992. Demonstration of a 7-nm RNP fiber as the basic structural element in a premessenger RNP particle. Exp. Cell Res. 199: 292-296.

Lynch, K.W. and T. Maniatis. 1995. Synergistic interactions between two distinct elements of a regulated splicing enhancer. Genes \& Dev. 9: 284-293.

Mähr, R., B. Meyer, B. Daneholt, and H.M. Eppenberger. 1980. Activation of Balbiani Ring genes in Chironomus tentans after a pilocarpine-induced depletion of the secretory products from the salivary gland lumen. Dev. Biol. 80: 409-418.

Mayeda, A. and A.R. Krainer. 1992. Regulation of alternative pre-mRNA splicing by hnRNP Al and splicing factor SF2. Cell 68: 365-375.

Mayeda, A., A.M. Zahler, A.R. Krainer, and M.B. Roth. 1992. Two members of a conserved family of nuclear phosphoproteins are involved in pre-messenger-RNA splicing. Proc. Natl. Acad. Sci. 89: 1301-1304.

Mayeda, A., S.H. Munroe, J.F. Cáceres, and A.R. Krainer. 1994. Function of conserved domains of hnRNP Al and other hnRNP A/B proteins. EMBO I. 13: 5483-5405.

Mehlin, H., B. Daneholt, and U. Skoglund. 1992. Translocation of a specific premessenger ribonucleoprotein particle through the nuclear pore studied with electron microscope tomography. Cell 69: 605-613.

- 1995. Structural interaction between the nuclear pore complex and a specific translocating RNP particle. $/$. Cell Biol. 129: 1205-1216.

Neugebauer, K.M., J.A. Stolk, and M.B. Roth. 1995. A conserved epitope on a subset of SR proteins defines a larger family of 
pre-mRNA splicing factors. I. Cell Biol. 129: 899-908.

Nevins, J.R. 1983. The pathway of eukaryotic mRNA formation. Annu. Rev. Biochem. 52: 441-466.

Olins, A.L., D.E. Olins, and W.W. Franke. 1980. Stereo-electron microscopy of nucleoli, Balbiani rings and endoplasmic reticulum in Chironomus salivary glands. Eur. I. Cell Biol. 22: 714-723.

Osheim, Y.N., O.L. Miller, Jr., and A.L. Beyer. 1985. RNP particles at splice junction sequences on Drosophila chorion transcripts. Cell 43: 143-151.

Piñol-Roma, S. and G. Dreyfuss. 1992. Shuttling of pre-mRNA binding proteins between nucleus and cytoplasm. Nature 355: 730-732.

Reed R. and T. Maniatis. 1986. A role for exon sequences and splice site proximity in splice site selection. Cell 46: 681-690.

Rice, C.M., R. Fuchs, D.G. Higgins, P.J. Stoehr, and G.N. Cameron. 1993. The EMBL data library. Nucleic Acids Res. 21: $2967-2971$.

Ring, H.Z. and J.T. Lis. 1994. The SR protein B52/SRp55 is essential for Drosophila development. Mol. Cell. Biol. 14: 7499-7506.

Robberson, B.L., G.J. Cote, and S.M. Berget. 1990. Exon definition may facilitate splice site selection in RNAs with multiple exons. Mol. Cell. Biol. 10: 84-94.

Roth, M.B., C. Murphy, and J.G. Gall. 1990. A monoclonal antibody that recognizes a phosphorylated epitope stains lampbrush chromosome loops and small granules in the amphibian germinal vesicle. I. Cell Biol. 111: 2217-2223.

Roth, M.B., A.M. Zahler, and J.A. Stolk. 1991. A conserved family of nuclear phosphoproteins localized to sites of polymerase II transcription. J. Cell Biol. 115: 587-596.

Screaton, G.R., I.F. Cáceres, A. Mayeda, M.V. Bell, M. Plebanski, D.G. Jackson, J.I. Bell, and A.R. Krainer. 1995. Identification and characterization of three members of the human SR family of pre-mRNA splicing factors. EMBO I. 14: 4336-4349.

Skoglund, U., K. Andersson,, B. Björkroth, M.M. Lamb, and B. Daneholt. 1983. Visualization of the formation and transport of a specific hnRNP particle. Cell 34: 847-855.

Skoglund, U., K. Andersson, B. Strandberg, and B. Daneholt. 1986. Three-dimensional structure of a specific pre-messenger RNP particle established by electron microscope tomography. Nature 319: 560-564.

Spector, D.L., X.-D. Fu, and T. Maniatis. 1991. Associations between distinct pre-mRNA splicing components and the cell nucleus. $E M B O$ I. 10: $3467-3481$.

Staknis, D. and R. Reed. 1994. SR proteins promote the first specific recognition of pre-mRNA and are present together with the U1 small nuclear ribonucleoprotein particle in a general splicing enhancer complex. Mol. Cell. Biol. 14: 7670-7682.

Stevens, B.J. and H. Swift. 1966. RNA transport from nucleus to cytoplasm in Chironomus salivary glands. J. Cell Biol. 31: 55-77.

Sümegi, J., L. Wieslander, and B. Daneholt. 1992. A hierarchic arrangement of the repetitive sequences in the Balbiani ring 2 gene of Chironomus tentans. Cell 30: 579-587.

Sun, Q., R.H. Hampson, and F.M. Rottman. 1993a. In vitro analysis of bovine growth hormone pre-mRNA alternative splicing: Involvement of exon sequences and transacting factor(s). J. Biol. Chem. 268: 15659-15666.

Sun, Q., A. Mayeda, R.K. Hampson, A.R. Krainer, and F.M. Rottman. 1993b. General splicing factor SF2/ASF promotes alternative splicing by binding to an exonic splicing enhancer. Genes \& Dev. 7: 2598-2608.

Talerico, M. and S.M. Berget. 1990. Effect of $5^{\prime}$ splice site mutations on splicing of the preceding intron. Mol. Cell. Biol. 10: 6299-6305.

Tanaka, K., A. Watakabe, and Y. Shimura. 1994. Polypurine sequences within a downstream exon function as a splicing enhancer. Mol. Cell. Biol. 14: 1347-1354.

Tian, M. and T. Maniatis. 1993. A splicing enhancer complex controls alternative splicing of doublesex pre-mRNA. Cell 74: $105-114$

1994. A splicing enhancer exhibits both constitutive and regulated activities. Genes \& Dev. 8: 1703-1712.

Tokuyasu, K.T. 1980. Immunochemistry on ultrathin frozen sections. Histochem. J. 12: 381-403.

Vellard, M., A. Sureau, J. Soret, C. Martinerie, and B. Perbal. 1992. A potential splicing factor is encoded by the opposite strand of the trans-spliced c-myb exon. Proc. Natl. Acad. Sci. 89: 2511-2515.

Visa, N., A. Alzhanova-Ericsson, X. Sun, E. Kiseleva, B. Björkroth, T. Wurtz, and B. Daneholt. 1996. A pre-mRNA-binding protein accompanies the RNA from the gene through the nuclear pores and into polysomes. Cell 84: 253-264.

von Heijne, G. 1988. Sequence analysis in molecular biology: Treasure trove or trivial pursuit. Academic Press, San Diego, CA.

Wang, J. and J.L. Manley. 1995. Overexpression of the SR proteins ASF/SF2 and SC35 influences alternative splicing in vivo in diverse ways. RNA 1: 335-346.

Wansink, D.G., W. Schul, I. van der Kraan, B. van Steensel, R. van Driel, and L. de Jong. 1993. Fluorescent labeling of nascent RNA reveals transcription by RNA polymerase II in domains scattered throughout the nucleus. $J$. Cell Biol. 122: 283-293.

Watakabe, A., H. Sakamoto, and Y. Shimura. 1991. Repositioning of an alternative exon sequence of mouse IgM pre-mRNA activates splicing of the preceding intron. Gene Expression 1: $175-184$.

Wieslander, L. 1994. The Balbiani ring multigene family: Coding repetitive sequences and evolution of a tissue-specific cell function. Prog. Nucleic Acid Res. Mol. Biol. 48: 275-313.

Wieslander, L. and G. Paulsson. 1992. Sequence organization of the Balbiani ring 2.1 gene in Chironomus tentans. Proc. Natl. Acad. Sci. 89: 4578-4582.

Wu, Z., C. Murphy, H.G. Callan, and J.G. Gall. 1991. Small nuclear ribonucleoproteins and heterogenous nuclear ribonucleoproteins in the amphibian germinal vesicle: Loops, spheres, and snurposomes. I. Cell Biol. 113: 465-483.

Wurtz, T., A. Lönnroth, L. Ovchinnikov, U. Skoglund, and B. Daneholt. 1990. Isolation and initial characterization of a specific premessenger ribonucleoprotein particle. Proc. Natl. Acad. Sci. 87: 831-835.

Wurtz, T., E. Kiseleva, G. Nacheva, A. Alzhanova-Ericsson, A. Rosén, and B. Daneholt. 1996. Identification of two RNAbinding proteins in Balbiani ring premessenger ribonucleoprotein granules and presence of these proteins in specific subsets of heterogenous nuclear ribonucleoprotein particles. Mol. Cell. Biol. 16: 1425-1435.

Wyss, C. 1982. Chironomus tentans epithelial cell lines sensitive to ecdysteroids, juvenile hormone, insulin and heat shock. Exp. Cell Res. 139: 309-319.

$\mathrm{Xu}, \mathrm{R} ., \mathrm{J}$. Teng, and T.A. Cooper. 1993. The cardiac troponin T alternative exon contains a novel purine-rich positive splicing element. Mol. Cell. Biol. 13: 3660-3674.

Zahler, A.M., W.S. Lane, J.A. Stolk, and M.B. Roth. 1992. SR proteins: A conserved family of pre-mRNA splicing factors. Genes \& Dev. 6: 837-847.

Zahler, A.M., K.M. Neugebauer, W.S. Lane, and M.B. Roth. 1993a. Distinct functions of SR proteins in alternative premRNA splicing. Science 260: 219-222.

Zahler, A.M., K.M. Neugebauer, J.A. Stolk, and M.B. Roth. 1993b. Human SR proteins and isolation of a cDNA encoding SRp75. Mol. Cell. Biol. 13: 4023-4028. 


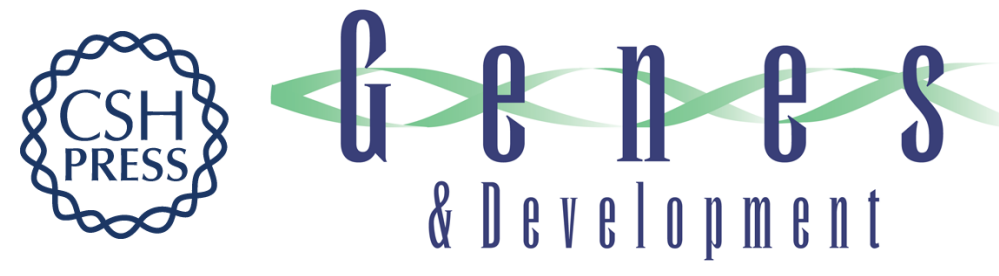

\section{A protein of the SR family of splicing factors binds extensively to exonic Balbiani ring pre-mRNA and accompanies the RNA from the gene to the nuclear pore.}

A T Alzhanova-Ericsson, $\mathrm{X}$ Sun, $\mathrm{N}$ Visa, et al.

Genes Dev. 1996, 10:

Access the most recent version at doi:10.1101/gad.10.22.2881

References This article cites 82 articles, 40 of which can be accessed free at:

http://genesdev.cshlp.org/content/10/22/2881.full.html\#ref-list-1

License

Email Alerting Service

Receive free email alerts when new articles cite this article - sign up in the box at the top right corner of the article or click here.

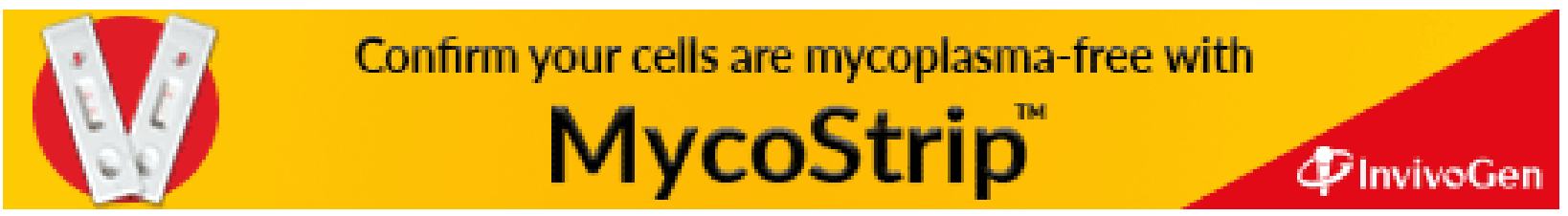

